\title{
Virtual hysterosalpingography using computed tomography, the first experiments in Brazil
}

\author{
Guilherme Galante Heuser ${ }^{1,2,3 *}$, Sandra Leontina Graube ${ }^{1,2,3}$, Tássia Machado Medeiros ${ }^{2,3}$, \\ Henrique Galante Heuser ${ }^{2,3}$, Rodrigo Dessuy Haag ${ }^{2,3}$, Camila Bohrer Bolsson ${ }^{2,3}$, Eliane Roseli Winkelmann ${ }^{1}$
}

Universidade Regional do Noroeste do Estado do Rio Grande do Sul (UNIJUÍ), Programa de Pós-graduação em Atenção Integral a Saúde, ljui, RS, Brasil ${ }^{2}$ Hospital Unimed Noroeste RS, Centro de Diagnóstico por Imagem, ljui, RS, Brasil

${ }^{3}$ Instituto de Medicina e Diagnóstico por Imagem (IMED Radiologia), ljui, RS, Brasil

\section{Abstract}

Objectives: This article demonstrates the virtual hysterosalpingography using computed tomography method used to perform the evaluation of tubal patency and uterine morphological alterations, which was carried out for the first time in Brazil, and our experience in this area. The techniques advantages, benefits and disadvantages compared to the traditional method are illustrated in this manuscript. Methods: 185 patients were submitted to virtual hysterosalpingography using computed tomography by a physicians indication and the results of these tests were compiled and described. Results: The advantages of virtual hysterosalpingography over X-ray hysterosalpingography are: (a) the variety of technological features offered by multi-detector tomography, (b) the injection pump and the workstations with software that allow post-processing of high-fidelity clinical images, and (c) not pinching the uterine cervix. Conclusions: Virtual hysterosalpingography is a viable alternative for the evaluation of tubal and uterine infertility factors.

Keywords: hysterosalpingography; virtual hysterosalpingography; conjugal infertility.

\section{Introduction}

Hysterosalpingography (HSG) is the most widely used method for assessing tubal patency and is often the first examination to be performed for a woman when the couple has infertility issues. ${ }^{1}$ In 2007 , Carrascosa et al. ${ }^{2}$ proposed performing virtual hysterosalpingography (V-HSG), which is an evaluation of the cavity and uterine tubes using tomography. This alternative method was developed from substantial improvements in hardware and software technology of radiological apparatuses which occurred in the last decade. In particular, the advent of the voxel made it possible to study smaller structures in a more efficient way, allowing reprocessed images of high clinical fidelity. ${ }^{3}$

The method consists of an extrapolation from the traditional method using X-rays to evaluate the morphology of the uterine cavity and tubal patency. ${ }^{3,4}$ The main advantage of this method is a significant reduction of pain, discomfort and vasovagal reactions experienced by patients, as it does not require pinching of the cervix and the injection of the contrast medium occurs under low pressure. ${ }^{1,4,5}$ The clinical indications and contraindications of the examination are equally extrapolations of the hysterosalpingography performed by X-rays. ${ }^{2}$

The technique of virtual hysterosalpingography was adapted to available technologies and materials, allowing efficient examination to be performed using low powered devices. Thus, this manuscript aims to describe the technique of adapted hysterosalpingography and its first experiments in Brazil, with 185 examinations already performed.

\footnotetext{
Financial support: None.

Conflicts of interest: The authors declare no conflicts of interest.

Submitted: September 15, 2017.

Accepted: June 08, 2018.

The study was carried out at Hospital Unimed Noroeste RS, Centro de Diagnóstico por Imagem and Instituto de Medicina e Diagnóstico por Imagem (IMED Radiologia), ljui, RS, Brasil.

Copyright Heuser et al. This is an Open Access article distributed under the terms of the Creative Commons Attribution License, which permits unrestricted use, distribution, and reproduction in any medium, provided the original work is properly cited.
} 


\section{Methods}

This is a case report study. We describe the technique used in the virtual hysterosalpingography exam in a private hospital in the northwest of the state of Rio Grande do Sul, Brazil. The sample consisted of 185 women who sought examination due to a physician's indication. These women accepted to participate in this research on conjugal infertility which was carried out from May 2015 to April 2017.

The patients were submitted to a directed anamnesis before the examination to identify possible risk factors for infertility, tubal obstruction and uterine morphostructural changes. In addition, after the examination, the patients filled out a questionnaire about their symptoms. The hysterosalpingography images were interpreted by two radiologists. All the patients who agreed to the examination signed a free and informed consent form and the study was approved by the ethics committee of the hospital and by the Research Ethics Committee of the University (CAAE number: 60799116.8.0000.5350).

\section{Results}

This manuscript describes the adapted virtual hysterosalpingography technique from the moment that the patient schedules her examination, as can be seen below.

When scheduling the exam, which should be performed between the 7th and 10th days of the menstrual cycle, patients are required to take a beta human chorionic gonadotropin (BhCG) serum test 48 hours prior to the virtual hysterosalpingography examination. In addition, it is requested that the patients bring a previous transvaginal ultrasound examination for comparative evaluation of uterine morphology and volume.

In the hospital, prior to the examination, a standard hospital questionnaire is applied to identify possible risk factors for allergies. This procedure is routine for all patients undergoing computed tomography, since iodine-based disinfectant is used topically in these patients and non-ionic iodinated contrast medium is instilled in the uterine cavity. To reduce the discomfort of the patients, one ampoule of scopolamine (Buscopan ${ }^{\circledR}$ ) is administered intravenously.

The exam is performed in a quiet, cozy room, and with the minimum number of support professionals possible. Patients are informed about all stages of the examination, including and especially about the possibility of discomfort during the injection of the contrast medium. These measures are taken to minimize apprehension of the patient, a factor that may influence the sensation of pain. ${ }^{6}$

For the examination, the patient is placed in the supine lithotomy position on the tomography table and the perineum is prepared with topical 10\% Povidone-iodine solution (PVPI) and sterile gauzes. Afterwards, vaginal dilation is performed with a plastic speculum of adequate size for the vaginal morphology of the patient. This allows access to the cervix, and then the vaginal and cervical cavity are disinfected with PVPI and sterile gauzes. Then, the 7 French hysterosalpingography balloon catheter is positioned in the proximal portion of the external cervical canal and the balloon is inflated.

The examinations were performed on an apneic patient using an Aquilion 32 slice computed tomography apparatus (Toshiba, Otawara, Japan) and post-processed on AWServer 4.1 workstation (General Electric Healthcare, Milwaukee, USA). The tomographic slices were obtained during the injection of the contrast medium. The slices were $0.5 \mathrm{~mm}$ thick in the caudocranial direction, beginning 3 seconds before the end of the injection. The contrast medium was diluted to $10 \%$ and injection was performed using an injection pump at a rate of $0.30 \mathrm{ml} / \mathrm{s}$. Image acquisition was stopped manually by the physician when the contrast medium was no longer seen in pelvic structures, in order to reduce the radiation dose received by these patients to the maximum extent.

The axial tomographic slices obtained were post-processed, performing multiplanar reconstruction (MPR) in sagittal and coronal planes, curved planes, maximum intensity projection (MIP), 3D volume rendering and virtual navigation video.

\section{Discussion}

There are significant advantages of virtual hysterosalpingography over hysterosalpingography performed by X-rays (Chart 1). These advantages are due to (a) the variety of technological features offered by multi-detector tomography; (b) the injection pump and the workstations with software that allow post-processing of high-fidelity clinical images; and (c) not pinching the uterine cervix.

By eliminating pinching of the uterine cervix, by the injection of contrast medium under low pressure and consequently lower uterine distension, virtual hysterosalpingography by tomography is a safe and comfortable option for evaluation of uterine morphology, tubal alterations and patency (Figure 1), with less discomfort and fewer cases of complications than the traditional exam. 2,3,5 Furthermore, V-HSG demands less execution time and requires less radiation dose than the traditional method. ${ }^{7}$

The main advantage is the reduction of discomfort and pain perceived by the patients..$^{3,5}$ There were no vasovagal reactions in our sample, which are the most common complications in HSG. ${ }^{8}$ In studies with larger samples comparing 
Chart 1. Comparison of the advantages and disadvantages of V-HSG over HSG

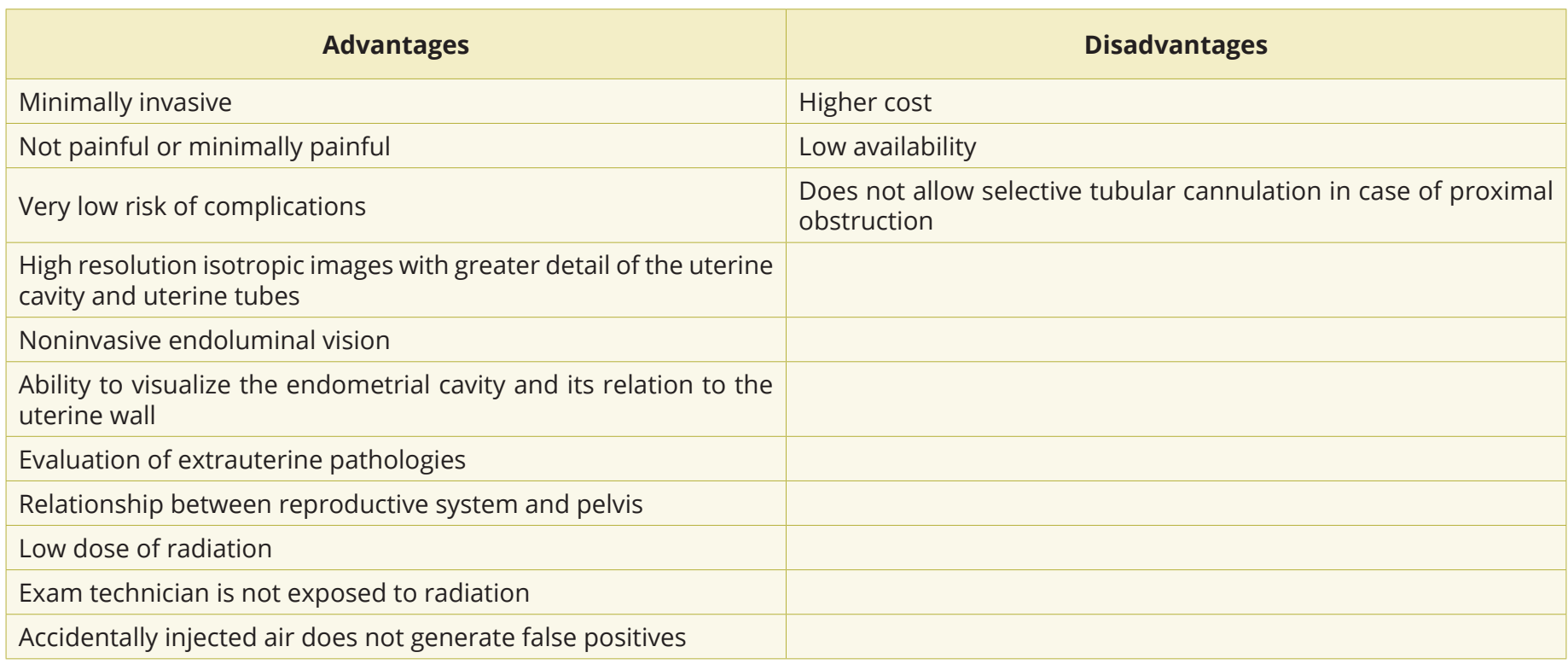

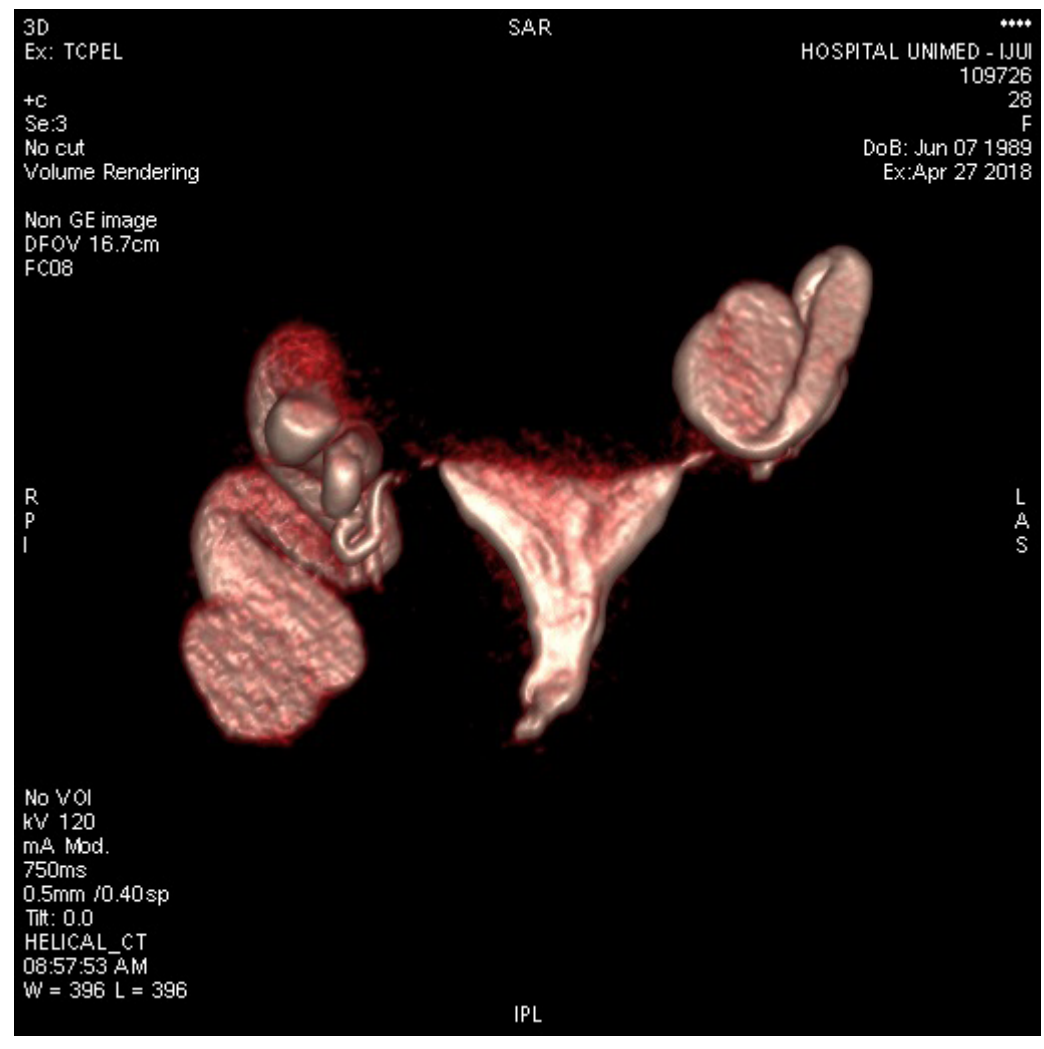

Figure 1. Bilateral hydrosalpin: Volume Rendering Imagin of a bilateral hydrosalpin.

the two techniques (V-HSG x HSG) a significantly lower number of vasovagal reactions were found in patients undergoing V-HSG. ${ }^{3,9}$ Furthermore, as an additional benefit of not requiring pinching of the uterine cervix, there is a lower risk of complications such as bleeding and infection. ${ }^{1,2,10}$

Diluted contrast media allow well-delimited images without artifacts that impair image analysis and are less irritating to the peritoneum than pure contrast media. ${ }^{2,8}$ As with HSG, gadolinium may be used as an alternative contrast medium in patients with a known history of iodine allergy, 3,11,12 with the only disadvantage being an increased cost of the procedure. 
Another recurring issue consists in quantifying the dose of radiation emitted since the focus of the examination covers the gonads of young patients who may wish to become pregnant. There is a lower incidence of radiation with V-HSG than HSG, an aspect already widely demonstrated in the literature.,312,13 Adding to this fact is the manual interruption of the acquisition of images when there is no longer any contrast in the field of view, which helps avoid unnecessary emission of radiation, following the principle ALARA (as low as reasonably achievable).

Highlighted among the advantages of V-HSG, when uterine cavity changes occur, the reconstruction and virtual navigation resources facilitate the assistant's understanding and the planning for the surgical approach. ${ }^{14,15}$ There is a greater ability to differentiate between the bicornuate uterus and the arcuate uterus (Figure 2), since V-HSG has the ability to show the uterine wall and its relationship with the endometrial cavity. 3,10,16 This definition is extremely important because the therapeutic approach of these patients differ significantly. ${ }^{16}$ Chart 1 presents a comparison of the advantages and disadvantages of V-HSG over HSG, as described above.

In our technique there were adaptations, the first makes the method easier to execute, and the second allows the use of lower power apparatus (Table 1).

The use of the balloon catheter was an adaptation performed because extreme difficulties in performing the test with non-balloon catheters were perceived. Additionally, the deformity of the proximal portion of the uterine cervix generated by the balloon was judged to not be decisive in the main outcome of the examination.

The second alteration performed by our team, which was considered fundamental for the success of the technique, was the acquisition of images during the injection of the contrast medium, and not after the injection, as originally proposed. ${ }^{3}$ This adaptation was performed because it was understood that by keeping the contrast flow active, even at low velocity, less false filling defects would be obtained in the uterine tubes, even with a lower power apparatus. ${ }^{17,18}$ Additionally, since the contrast medium was being injected at low speed, there were no flow artifacts. ${ }^{17,19}$ Table 1 compares the main technical factors proposed by Carascosa ${ }^{3}$ and our image acquisition protocol.

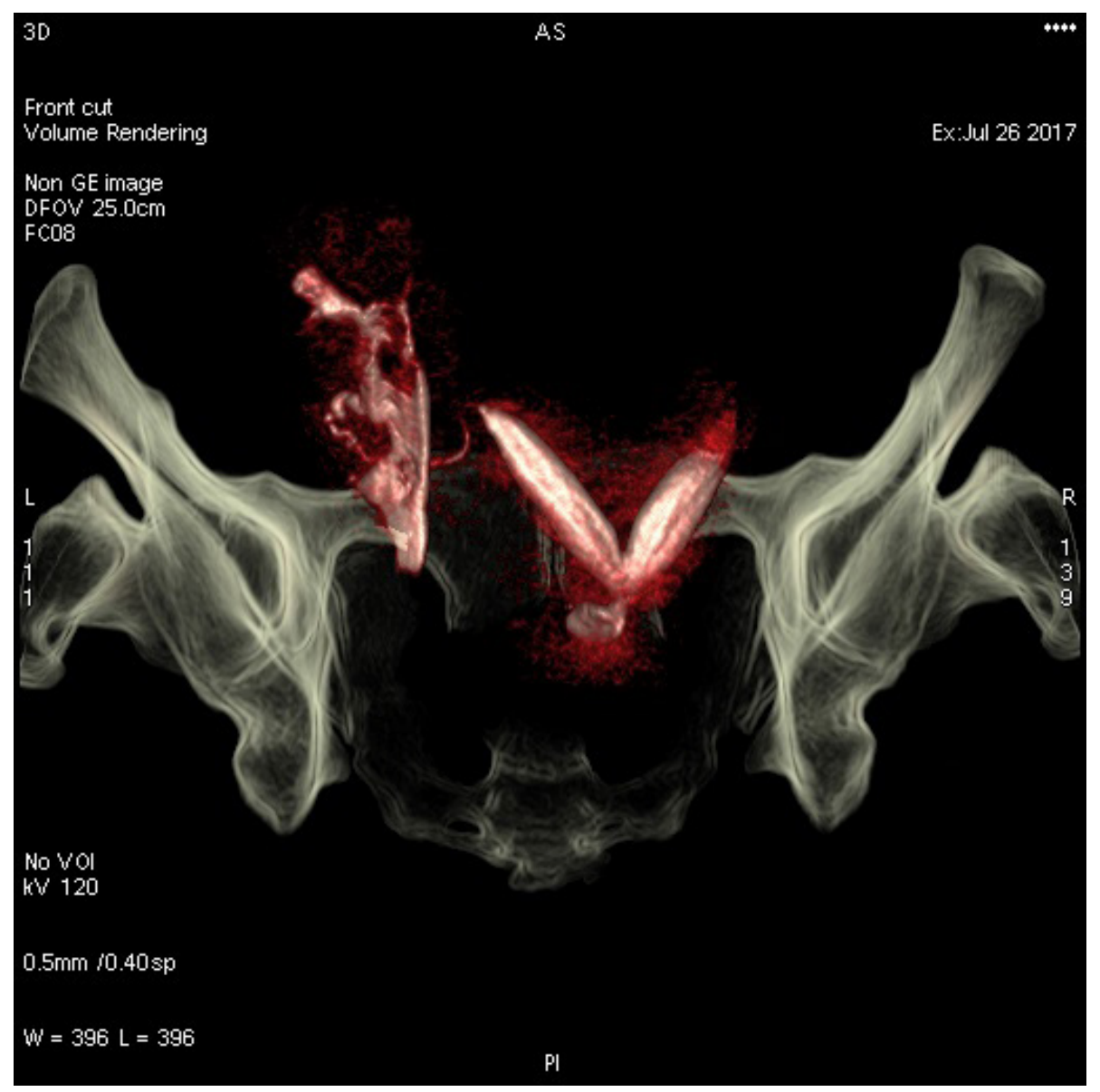

Figure 2. bicornuated uterus. Volume rendering imaging of a bicornuated uterus vith tubal obstruction in the right horn. 
Table 1. Comparison of the technical parameters between the protocols for virtual hysterosalpingography proposed by Carrascosa and by the present study

$\begin{array}{lcc} & \text { Carrascosa et al. } & \text { Present study } \\ \text { Number of detectors } & 64 \text { or more } & 16 \text { or more } \\ \text { Catheter } & \text { Without balloon } & \text { With balloon } \\ \text { Dilution of ICM, } \% & 17 & 10 \\ \text { Injection speed, ml/s } & 0.3 & 0.3 \\ \text { Slice thickness, mm } & 0.9 & 0.5 \\ \text { Image acquisition moment } & \text { After injection } & \text { During injection } \\ \text { Detector collimation, mm } & 64 \times 0.625 & 32 \times 0.5 \\ \text { Reconstruction interval, mm } & 0.45 & 0.40 \\ \text { Kv } & 120 & 120 \\ \text { mA } & \text { Automatic (120-250) } & \text { Automatic (120-250) } \\ \text { Time for acquisition, sec } & 3 \text { a } 4 & 22\end{array}$

$\mathrm{Kv}=$ kilovolts; $\mathrm{mA}=$ milliamperes; ICM = iodinated contrast medium.

\section{Conclusion}

Traditional hysterosalpingography responds satisfactorily to issues related to tubal abnormalities and patency associated with female infertility, however, habitual discomfort and frequent vasovagal reactions make this examination quite feared by patients. Virtual hysterosalpingography, the method described in the present experiment report, is a viable alternative for the assessment of tubal and uterine infertility factors.

\section{Acknowledgements}

Northwest Rio Grande do Sul Unimed for giving up the research space and patients for their participation in the research.

\section{References}

1. Kaproth-Joslin K, Dogra V. Imaging of female infertility: a pictorial guide to the hysterosalpingography, ultrasonography, and magnetic resonance imaging findings of the congenital and acquired causes of female infertility. Radiol Clin North Am. 2013;51(6):967-81. http://dx.doi.org/10.1016/j.rcl.2013.07.002. PMid:24210439.

2. Carrascosa P, Capuñay C, Mariano B, López EM, Jorge C, Borghi M, et al. Virtual hysteroscopy by multidetector computed tomography. Abdom Imaging. 2008;33(4):381-7. http://dx.doi.org/10.1007/s00261-007-9270-9. PMid:17619924.

3. Carrascosa PM, Capuñay C, Vallejos J, Martín López EB, Baronio M, Carrascosa JM. Virtual hysterosalpingography: a new multidetector CT technique for evaluating the female reproductive system. Radiographics. 2010;30(3):643-661. http://dx.doi.org/10.1148/ rg.303095732. PMid:20462986.

4. Pérez JA, Maurer MN, Abreu M, Pitrez LH, Pellanda RC, Maurer SAC, et al. Prevalência de alterações uterinas e tubárias na histerossalpingografia em mulheres inférteis: estudo de 48 casos. Radiol Bras. 2001;34(2):79-81. http://dx.doi.org/10.1590/ S0100-39842001000200005.

5. Carrascosa P, Capuñay C, Vallejos J, Carpio J, Baronio M, Papier S. Two-dimensional and three-dimensional imaging of uterus and fallopian tubes in female infertility. Fertil Steril. 2016;105(6):1403-1420.e7. http://dx.doi.org/10.1016/j.fertnstert.2016.04.016. PMid:27140290.

6. Lindheim SR, Sprague C, Winter TC 3rd. Hysterosalpingography and sonohysterography: lessons in technique. AJR Am J Roentgenol. 2006;186(1):24-9. http://dx.doi.org/10.2214/AJR.05.0836. PMid:16357372.

7. Carrascosa P, Baronio M, Capuñay C, López EM, Sueldo C, Papier S. Clinical use of 64-row multislice computed tomography hysterosalpingography in the evaluation of female factor infertility. Fertil Steril. 2008;90(5):1953-8. http://dx.doi.org/10.1016/j. fertnstert.2007.09.033. PMid:18222438.

8. Liberty G, Gal M, Halevy-Shalem T, Michaelson-Cohen R, Galoyan N, Hyman J, et al. Creme de lidocaína-prilocaína (EMLA) como analgesia para histerosalpingografia: estudo prospectivo, randomizado, controlado, duplamente cego. Hum Reprod. 2007;22(5):1335-9. PMid:17234675. 
9. Carrascosa P, Baronio M, Capuñay C, López EM, Vallejos J, Borghi M, et al. Multidetector computed tomography virtual hysterosalpingography in the investigation of the uterus and fallopian tubes. Eur J Radiol. 2008;67(3):531-5. http://dx.doi. org/10.1016/j.ejrad.2007.08.004. PMid:17870273.

10. Carrascosa P, Capuñay C, Baronio M, Martín López E, Vallejos J, Borghi M, et al. 64-Row multidetector CT virtual hysterosalpingography. Abdom Imaging. 2009;34(1):121-33. http://dx.doi.org/10.1007/s00261-008-9432-4. PMid:18709407.

11. Belt MM, Rodenko G, Taylor K, Maguire C, Bello S. Use of gadolinium for hysterosalpingography in iodine allergic women: a case-control study. Fertil Steril. 2008;90(3):835-8. http://dx.doi.org/10.1016/j.fertnstert.2007.02.019. PMid:18371957.

12. Noorhasan D, Heard MJ. Gadolinium radiologic contrast is a useful alternative for hysterosalpingography in patients with iodine allergy. Fertil Steril. 2005;84(6):1744.e5. http://dx.doi.org/10.1016/j.fertnstert.2005.06.032. PMid:16359979.

13. Carrascosa P, Capuñay C, Vallejos J, Baronio M, Carrascosa J. Virtual hysterosalpingography: experience with over 1000 consecutive patients. Abdom Imaging. 2011;36(1):1-14. http://dx.doi.org/10.1007/s00261-010-9616-6. PMid:20458478.

14. Celik O, Karakas HM, Hascalik S, Tagluk ME. Virtual hysterosalpingography and hysteroscopy: assessment of uterine cavity and fallopian tubes using 64-detector computed tomography data sets. Fertil Steril. 2010;93(7):2383-4. http://dx.doi.org/10.1016/j. fertnstert.2009.05.027. PMid:19559413.

15. Akaeda T, Isaka K, Nakaji T, Kakizaki D, Abe K. Clinical application of virtual hysteroscopy by CO(2)-multidetector-row computed tomography to submucosal myomas. J Minim Invasive Gynecol. 2005;12(3):261-6. http://dx.doi.org/10.1016/j.jmig.2005.03.001. PMid:15922985.

16. Carrascosa P, Sueldo C, Capuñay C, Baronio M, Papier S. Virtual hysterosalpingography in the diagnosis of bicornuate versus septate uterus. Fertil Steril. 2011;96(5):1190-2. http://dx.doi.org/10.1016/j.fertnstert.2011.08.026. PMid:21944930.

17. Weininger M, Barraza JM, Kemper CA, Kalafut JF, Costello P, Schoepf UJ. Cardiothoracic CT angiography: current contrast medium delivery strategies. AJR Am J Roentgenol. 2011;196(3):W260-72. http://dx.doi.org/10.2214/AJR.10.5814. PMid:21343473.

18. Bae KT. Intravenous contrast medium administration and scan timing at CT: considerations and approaches. Radiology. 2010;256(1):32-61. http://dx.doi.org/10.1148/radiol.10090908. PMid:20574084.

19. Kitagawa K, George RT, Arbab-Zadeh A, Lima JA, Lardo AC. Characterization and correction of beam-hardening artifacts during dynamic volume CT assessment of myocardial perfusion. Radiology. 2010;256(1):111-8. http://dx.doi.org/10.1148/radiol.10091399. PMid:20574089.

\section{*Correspondence}

Guilherme Galante Heuser

Universidade Regional do Noroeste do Estado do Rio Grande do Sul (UNIJUí)

Rua Rubem Mendes, 516, Morada do Sol

CEP 98700-000, ljuí, RS, Brasil

Tel.: +55 (55) 3332-0444

E-mail: guilherme@imedradioloiga.com.br

\section{Authors information}

GGH - Doctor; Master's Degree in Integral Health Care, Universidade Regional do Noroeste do Estado do Rio Grande do Sul. SLG - Nurse; Specialization in Strategic Management of Health Cooperativesslg, Universidade Regional do Noroeste do Estado do Rio Grande do Sul. TMM Biomedical; Master's Degree in Cell and Molecular Biology, Universidade Federal do Rio Grande do Sul. HGH - Doctor; Residency in Radiology and Diagnostic Imaging, Hospital Moinhos de Vento. RDH - Doctor; Residency in Radiology and Diagnostic Imaging, Ernesto Dorneles. CBB - Doctor; Residency in Radiology and Diagnostic Imaging, Brazilian College of Radiology. ERW - Physiotherapist; Doctorate's Degree in Cardiovascular Sciences, Universidade Federal do Rio Grande do Sul.

\section{Authors contribution}

GGH conceived the experiment and wrote the main text, formatting and normalization of the article for submission to the journal and conducted the experiment. SLG, TMM, HGH, RDH, CBB conducted the experiment. ERW project orientation, writing, reading and correction of the article. All authors reviewed and approved the manuscript. 